\title{
THE EFFECTS OF ADRENOCORTICAL HORMONES ON ALBUMIN METABOLISM STUDIED WITH ALBUMIN-I'131
}

\author{
By M. A. ROTHSCHILD, S. S. SCHREIBER, M. ORATZ, ANd H. L. McGEE \\ (From the Radioisotope Service, Veterans Administration Hospital, and the Department of \\ Medicine, New York University College of Medicine, New York, N. Y.)
}

(Submitted for publication February 24, 1958; accepted May 2, 1958)

Previous studies of serum albumin turnover, employing albumin- $\mathrm{I}^{131}$ as a tracer, have revealed a narrow range of values averaging about $200 \mathrm{mg}$. per $\mathrm{Kg}$. per day in normal male adults and in patients with congestive heart failure $(1,2)$. In other disease states, abnormalities in the rate of synthesis or of degradation or of both have been observed. In patients with marked proteinuria, the amount of albumin undergoing metabolic degradation was found to be diminished significantly in most cases, whereas the rate of synthesis remained at normal levels (2). In contrast, the abnormally high rate of albumin catabolism in thyrotoxicosis was observed to be compensated by an augmented synthesis of albumin (3).

The major effect of the adrenocortical hormones on protein metabolism has been interpreted as an increased rate of catabolism (4), a decreased rate of synthesis (5) or a combination of both effects $(6,7,8)$. It appeared to be of interest to study the influence of these hormones on serum albumin metabolism since methods have been developed (3) that readily permit distinction between catabolic and antianabolic effects on serum albumin even under nonsteady state conditions. The present study is concerned with alterations in the rates of synthesis and degradation of serum albumin following treatment of rabbits and human subjects with steroid hormones.

\section{METHODS}

Eight healthy female rabbits were kept in metabolism cages and fed a standard Rockland rabbit diet, ad lib. Lugol's solution was added to the drinking water daily. During the period of cortisone administration, each rabbit received $40 \mathrm{mg}$. of streptomycin intramuscularly and 75,000 units of penicillin intramuscularly every other day to prevent infection. At the onset of cortisone administration, 5 to $8 \mathrm{mEq}$. of potassium chloride was added to

1 This material was presented in part at the meeting of the Eastern Section of the American Federation for Clinical Research on December 6, 1957. the drinking water, of which the animals consumed a quantity equivalent to 2 to $3 \mathrm{mEq}$. of potassium chloride daily.

The distribution and metabolism of albumin were studied by means of $\mathrm{I}^{131}$ labeled rabbit serum albumin. Following the intravenous administration of albumin- ${ }^{121}$, assays of $I^{131}$ in plasma, stool and urine were made for a control period of 10 to 14 days and continued through an experimental period of another 13 to 19 days, during which time cortisone acetate was given subcutaneously in doses of $3 \mathrm{mg}$. per $\mathrm{Kg}$. per day for the first 5 days and $1.5 \mathrm{mg}$. per $\mathrm{Kg}$. per day thereafter. A second dose of albumin- $\mathrm{I}^{131}$ was administered at the end of this period and observations were continued for another 9 to 16 days, during which time the animals continued to receive cortisone. Injections of albumin- $\mathrm{I}^{131}$ were made into an ear vein and 0.3 to $0.5 \mathrm{ml}$. of heparinized venous blood was obtained from the opposite ear 6 minutes and $10 \mathrm{~min}$ utes later and at daily intervals for one week, and every second to third day thereafter. The six minute serum sample was separated by paper electrophoresis in a veronal buffer, $\mathrm{pH} 8.6(\mu=0.05)$. A single radioactive peak was observed migrating with the albumin band (Figure 1). Paper electrophoretograms of rabbit serum, following the administration of $250 \mu \mathrm{c}$. of sodium iodide, were stained and washed in the same fashion as that shown in Figure 1. No significant evidence of radioactivity was obtained. Twenty-four hour urine and stool collections were obtained daily except in occasional instances when pooled weekend collections were made.

One hundred and fifty $\mu \mathrm{c}$. of iodinated pooled human serum albumin, ${ }^{2}$ with a specific activity not greater than $50 \mu \mathrm{c}$. per mg., was administered intravenously to five male patients at the New York Veterans Administration Hospital, and observations on plasma and urinary $I^{131}$ were made for control periods of 14 to 19 days, following which adrenocortical hormones were administered and observations continued for another 13 to 20 days. A second injection of albumin- $\mathrm{I}^{131}$ was then made and observations were continued for 14 to 19 days, during which time hormone administration was continued in all subjects except Patient T. H. Patients J. O., J. A. and $\mathrm{T}$. $\mathrm{H}$. received prednisone $10 \mathrm{mg}$. three times daily by mouth. Patient A. V. received hydrocortisone $150 \mathrm{mg}$.

2 Salt poor pooled human serum albumin, obtained from Cutter Laboratories, California, was used in these studies. Paper electrophoresis of this material revealed a single sharp band both before and after iodination. Iodination was performed as previously described (1). 


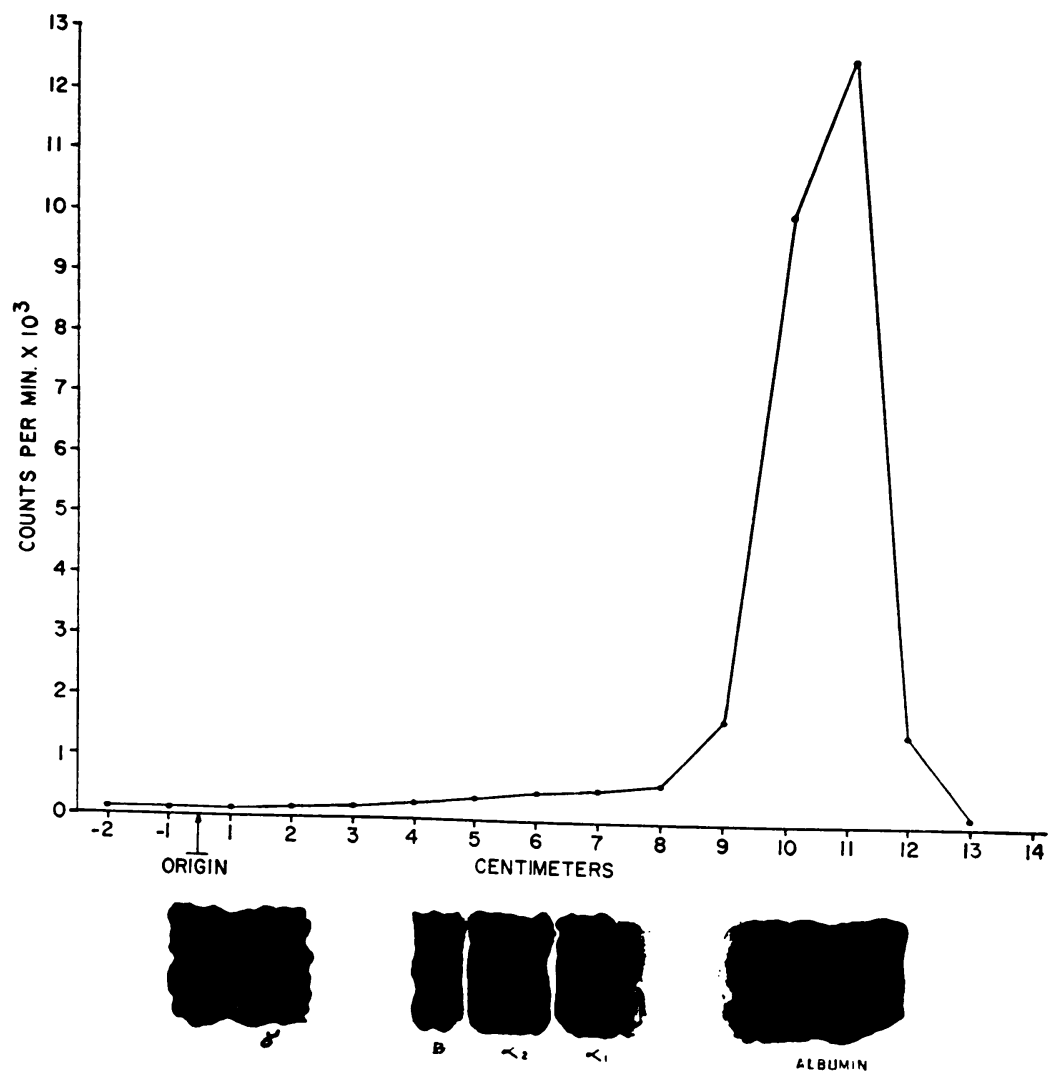

Fig. 1. Paper Radioelectrophoretogram of a Six Minute Sample of RabBit Plasma

daily orally and Patient $T$. W. received prednisone 10 mg. orally three times daily for 10 days and then twice daily. On the thirteenth day of drug administration, $\mathrm{Pa}-$ tient $\mathrm{T}$. $\mathrm{H}$. developed gastrointestinal complaints and prednisone was discontinued on the day of the second albumin- $\mathrm{I}^{131}$ injection. The patients received 10 drops of Lugol's solution twice daily and were maintained on a low salt diet without a potassium supplement.

Plasma samples were obtained from the arm opposite to the side of injection at 15,18 and 21 minutes and at almost daily intervals thereafter. Daily urine collections were obtained except for an occasional pooled week-end sample.

The rabbit albumin was prepared by zone electrophoresis on a Geon 426 block in a veronal buffer, $\mathrm{pH} 8.6$ $(\mu=0.075)$. Five $\mathrm{ml}$. of pooled rabbit serum was added to the block as a narrow band. The apparatus was placed in a cold room at 4 to $7^{\circ} \mathrm{C}$. and a potential of 600 volts was applied for 24 hours. The albumin band was located by placing the edge of a strip of Whatman $3 \mathrm{MM}$ paper along the longitudinal axis of the block. When the liquid phase reached a height of $5 \mathrm{~mm}$., the paper was removed, dried at $110^{\circ} \mathrm{C}$. for 30 minutes and stained with bromphenol blue. The albumin zone on the resin block was divided into four bands and the two middle bands were eluted with saline. The eluate was dialyzed against distilled water, lyophilized to a small volume, and rerun on a Geon 426 block. The final preparation ran as a single component. The middle fraction of the albumin was eluted as before and lyophilized to a dry solid after dialysis. The albumin was iodinated as described previously (1) and contained approximately 1 iodine atom per protein molecule with a specific activity not greater than $50 \mu \mathrm{c}$. per mg. of protein.

Plasma, urine and stool samples were assayed for radioactivity in a well-type scintillation counter with a sensitivity of $9.7 \times 10^{5}$ counts per minute per $\mu \mathrm{c}$. $\mathrm{I}^{131}$ above a background of approximately 170 counts per minute. Total serum protein was determined by the Kjeldahl method and serum albumin concentration was determined by the method of Kingsley (9) at 4 to 7 day intervals throughout the period of study. Control and experimental sera were analyzed by free and zone electrophoresis at $\mathrm{pH}$ 8.6. No significant differences in the alpha globulin fractions were observed. Urine was tested for protein by precipitation with cold trichloracetic acid and blood sugar was determined by the method of Somogyi (10).

Plasma volume was determined from the space of distribution of albumin- $\mathrm{I}^{131}$ at 6 and 10 minutes in the 
animals and at 15 and 18 minutes in the patients. Total exchangeable albumin and the extravascular and intravascular distribution of albumin were determined according to methods described previously (1). The rate of albumin metabolism during the control period was determined by two methods, as $(A)$ the product of total exchangeable albumin and the rate constant of decline in plasma radioactivity after distribution equilibrium, and $(B)$ as the product of the "metabolic clearance" of albumin- $\mathrm{I}^{191}$ and the serum albumin concentration. These methods have been described in detail in previous reports $(1,3,11)$. It has been pointed out previously that an advantage of the metabolic clearance method is that it can be applied in nonsteady state conditions ( 3 , 12). The total amount of albumin degraded over each period was obtained from the sum of the daily values for degradation determined by the metabolic clearance method. During the control periods, the serum albumin concentrations remained constant, and for practical purposes, it was assumed that steady state conditions, in terms of albumin metabolism, were satisfied. The quantity of albumin synthesized during these control periods was taken to be equivalent to the amount degraded. The quantity of albumin synthesized during cortisone administration was obtained from the difference between the total amount degraded and the change in the total exchangeable albumin pool.

\section{RESULTS}

Results pertaining to the animal studies are summarized in Table I. During cortisone administration a drop in serum albumin concentration occurred in seven of the eight rabbits, the mean value decreasing from 4.47 grams per cent to 3.79 grams per cent, a decrease of 11.2 per cent. Plasma volume increased in all animals with a mean value of plus 23 per cent. Mean values for albumin degradation (and albumin synthesis) during the control period determined by methods $(A)$ and $(B)$ were 1.51 and 1.52 grams per day, respectively. During cortisone administration the quantity of albumin degraded increased in all animals (Table I, Figure 2) to an average value of 2.4 grams per day. The total increase in albumin degradation during the period of treatment ranged from 6.8 grams to 20.0 grams, with a mean value of 13.1 grams. Since the mean total exchangeable albumin decreased only slightly from 18.1 to 17.0 grams, synthesis of albumin must have increased by an average of 12.0 grams during the experimental period. The extravascular albumin diminished during cortisone administration in all but one animal.

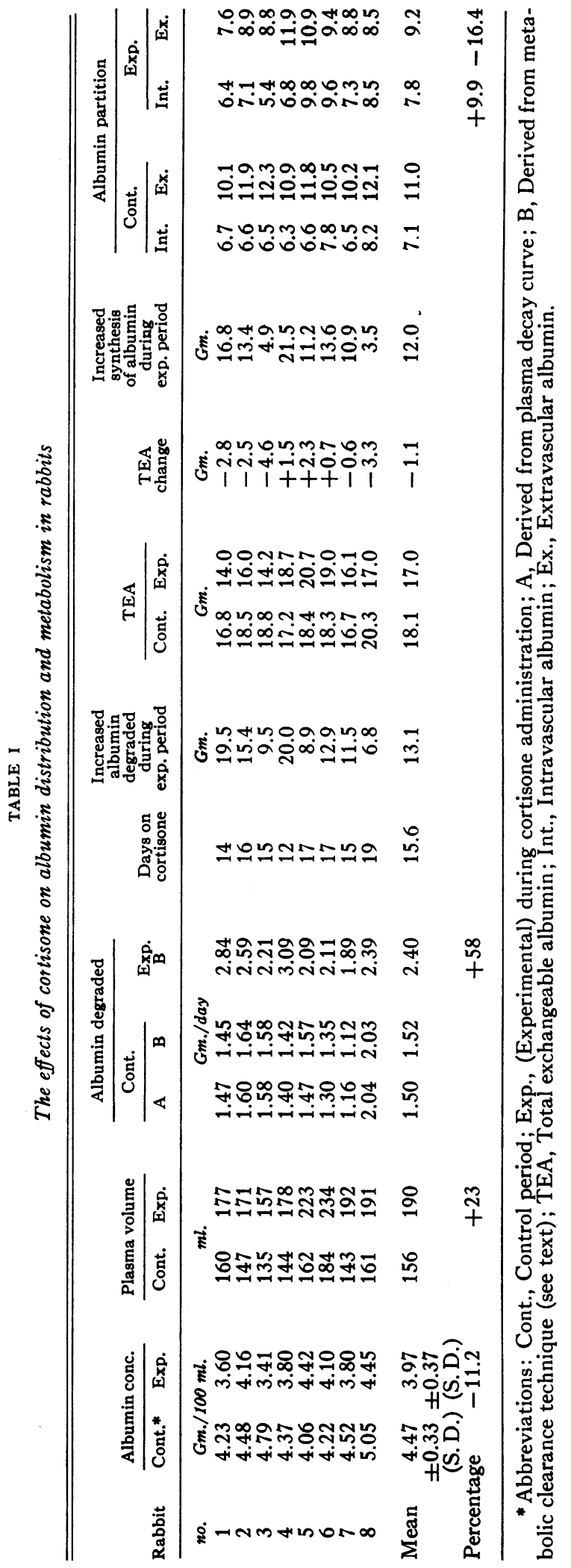



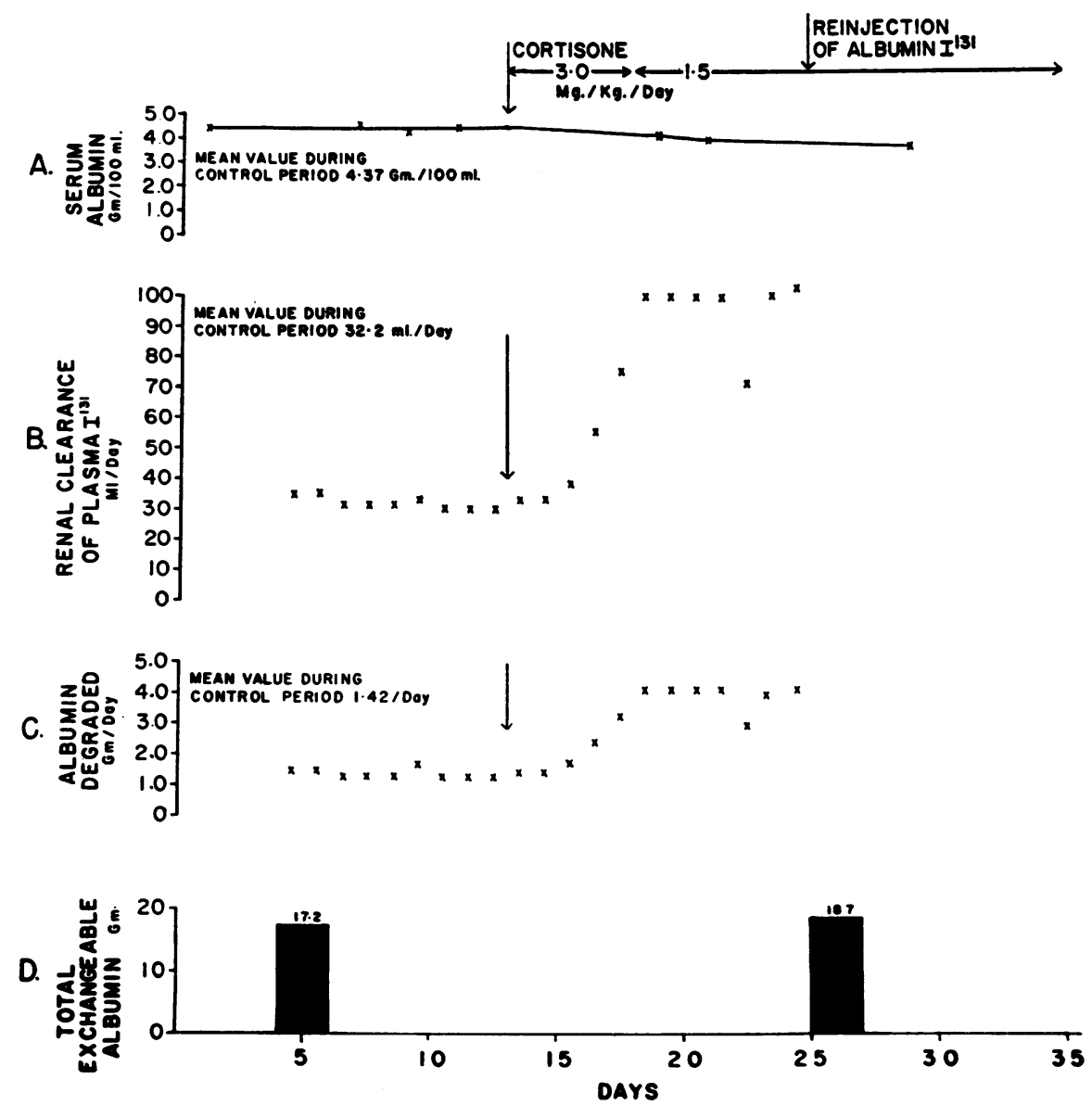

Fig. 2. Typical Animal Experiment, Rabbit No. 4

Following cortisone administration, there was a slow progressive fall in serum albumin concentration (Curve A), a marked rise in the renal clearance of plasma $I^{181}$ (Curve B) and $a$ rise in the quantity of albumin degraded (Curve $C$ ). Total exchangeable albumin increased slightly (Bar Graphs D).

The nonfasting blood sugars ranged from 95 to $268 \mathrm{mg}$. per cent in the seven animals in which it was measured. All of the animals revealed intermittent glycosuria within 48 to 72 hours after the institution of cortisone therapy. There was no significant change in the animals' weights from the control through the experimental periods. Hematocrit values fell in all animals with a mean decrease of 11.5 per cent. Proteinuria was not present in any of the animals.

The human studies are summarized in Table II. Patient W. T. is separated from the other subjects because this patient's control value for albumin turnover (312 mg. per Kg. per day) was significantly increased above normal values. Total se- rum protein concentration fell in all the cases and was attributable primarily to a decrease in the globulin fraction. The changes in plasma volume were negligible except in one case (T. H.), where there was a decrease of 9 per cent. The mean rates of albumin degradation during the control period were 14.7 grams per day and 13.9 grams per day by methods $(A)$ and $(B)$, respectively. During the experimental period a mean value of 17.7 grams per day was obtained (method B). Albumin degradation in excess of that during the control period ranged from 32 to 88 grams with a mean value of 59 grams. Since total exchangeable albumin decreased in these four subjects by 31 grams (range, 22 to 38 grams), the calculated 


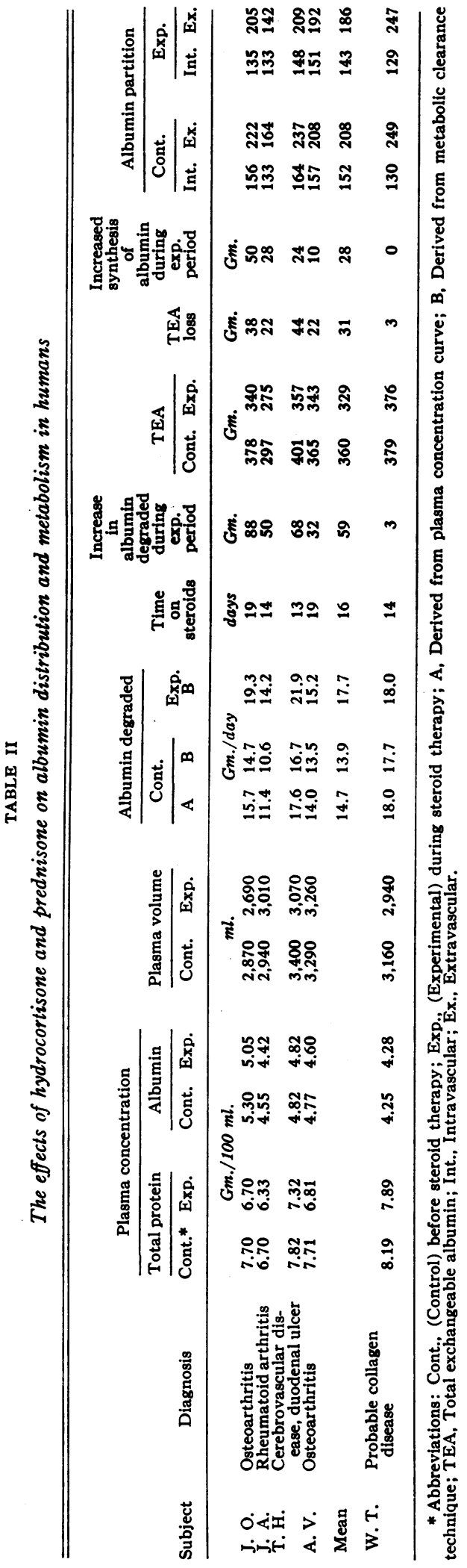

increase in synthesis averaged 28 grams (range, 10 to 50 grams). Loss in total exchangeable albumin occurred from both intravascular and extravascular compartments, with the major fraction coming from the extravascular stores. The patients' weights remained constant, no significant change in hematocrit values was observed, and proteinuria was not observed.

Patient W. T., who showed a greater than normal albumin turnover during the control period, was ill with an acute febrile illness considered to be a "collagen disease." Following the institution of prednisone, there was a steady clinical improvement, with remission of all symptoms. However, no significant changes in albumin turnover or distribution were observed during the course of these studies.

\section{DISCUSSION}

Although an increased loss of urinary nitrogen frequently accompanies the administration of excess adrenocortical hormones $(4,6,13-17)$, it has been emphasized that such excretory data only reflect the overall picture (17), for while some tissues are particularly susceptible to the wasting action of these hormones (18-23), others such as the liver, gastrointestinal tract and urogenital organs may actually show a positive nitrogen balance $(13,15,17)$. The present studies indicate that serum albumin metabolism is significantly altered during the administration of certain adrenocortical hormones. There is a moderate to marked increase in the rate of albumin catabolism associated with an increase of similar magnitude in the rate of albumin synthesis, so that there results only a negligible loss of body albumin stores. These observations clearly provide no support for the thesis that these hormones exert an antianabolic effect on all protein metabolism. The small defect in albumin balance was derived mainly from the extravascular stores, a finding which has also been recorded following the administration of large doses of desiccated thyroid (3).

The alterations in albumin metabolism were not as great in the human subjects as in the rabbits. This fact probably relates both to the different drugs and dosage schedules employed. However, the findings were qualitatively the same in 
both species and agree in substance with the preliminary report of Grossman, Yalow and Weston (24). Blythe and co-workers (25) have also reported, in abstract form, an increased rate of albumin degradation following the daily administration of $300 \mathrm{mg}$. of hydrocortisone to human subjects. The acutely ill patient, W. T., was probably under the influence of increased adrenocortical stimulation secondary to the active disease process, which may explain the lack of increase in this patient's already rapid albumin turnover following the administration of exogenous adrenocortical hormone.

The validity of methods employing albumin- $\mathrm{I}^{131}$ for the measurement of albumin metabolism and albumin distribution has been subjected to extensive critical review elsewhere $(1,2,12)$. It would seem unnecessary to enter into a similar discussion here. However, it may be pointed out that McFarlane (26) has obtained almost identical values for albumin metabolism in rabbits employing albumin- $\mathrm{I}^{131}$ labeled in vitro and biosynthetically labeled albumin- $\mathrm{C}^{14}$, and Berson and Yalow (12) have emphasized that available data for human subjects indicates similar rates of metabolism of albumin- $\mathrm{I}^{131}$ and endogenously labeled albumin- $S^{35}$ when account is taken of reutilization of the latter label (12). A major difficulty in the use of albumin-I ${ }^{131}$ in the past has been in the preparation of undenatured material $(1,12$, 26), but the albumin- $\mathrm{I}^{131}$ used in the present studies has given values almost identical to those obtained with the best preparations reported elsewhere in rabbits $(27)$ and man $(1,2)$. Furthermore, since all studies in the present report employed the same dose of albumin- $\mathrm{I}^{131}$ for control and experimental periods, the observed changes cannot be attributed to variations in the preparations.

\section{SUMMARY AND CONCLUSIONS}

1) The distribution and metabolism of albumin employing species specific albumin- $\mathrm{I}^{181}$ were studied in eight female rabbits and five male patients before and during the administration of adrenocortical hormones.

2) Under the influence of cortisone, albumin degradation increased by 58 per cent in the animals and augmented albumin synthesis compen- sated for 91 per cent of this increased albumin destruction. In the human experiments, albumin degradation increased 27 per cent while increase in synthesis replaced 48 per cent of the albumin degraded in excess of the control values.

\section{ACKNOWLEDGMENTS}

The authors wish to express their appreciation to Mrs. Geraldine Mullings for secretarial assistance, to $\mathrm{Mr}$. Robert Downing, Mr. Douglas Faison, and Mr. John Tolbert for their technical assistance, and to Miss Josephine Neglia for the illustrations.

\section{REFERENCES}

1. Berson, S. A., Yalow, R. S., Schreiber, S. S., and Post, J. Tracer experiments with $\mathrm{I}^{181}$ labeled human serum albumin: Distribution and degradation studies. J. clin. Invest. 1953, 32, 746.

2. Bauman, A., Rothschild, M. A., Yalow, R. S., and Berson, S. A. Distribution and metabolism of $\mathrm{I}^{181}$ labeled human serum albumin in congestive heart failure, with and without proteinuria. J. clin. Invest. 1955, 34, 1359.

3. Rothschild, M. A., Bauman, A., Yalow, R. S., and Berson, S. A. The effect of large doses of desiccated thyroid on the distribution and metabolism of albumin- $\mathrm{I}^{182}$ in euthyroid subjects. J. clin. Invest. $1957,36,422$.

4. Long, C. N. H., Katzin, B., and Fry, E. G. Adrenal cortex and carbohydrate metabolism. Endocrinology 1940, 26, 309.

5. Albright, F. Cushing's syndrome: Its pathologic physiology; its relationship to the adreno-genital syndrome and its connection with the problem of the reaction of the body to injurious agents ("Alarm Reaction" of Selye). Harvey Lect. 1942-1943, 38, 123.

6. Hoberman, H. D. Endocrine regulation of amino acid and protein metabolism during fasting. Yale J. Biol. Med. 1950, 22, 341.

7. Cannon, P. R., Frazier, L. E., and Hughes, R. H. The influence of cortisone upon protein metabolism. Arch. Path. (Chicago) 1956, 61, 271.

8. Parson, W., Crispell, K. R., and Ebbert, A., Jr. Abnormalities in $\mathrm{N}^{15}$ excretion rates after ingestion of tagged glycine in Cushing's syndrome and following ACTH administration. J. clin. Invest. 1952, 31, 548.

9. Kingsley, G. R. A rapid method for the separation of serum albumin and globulin. J. biol. Chem. 1940, 133, 731.

10. Somogyi, M. Notes on sugar determination. J. biol. Chem. 1952, 195, 19.

11. Berson, S. A., and Yalow, R. S. Quantitative aspects of iodine metabolism. The exchangeable organic iodine pool and the rates of thyroidal secretion, peripheral degradation and fecal excretion of en- 
dogenously synthesized organically bound iodine. J. clin. Invest. 1954, 33, 1533.

12. Berson, S. A., and Yalow, R. S. Distribution and metabolism of $\mathrm{I}^{131}$ labeled proteins in man. Fed. Proc. 1957, 16, Suppl. 1, $13 S$.

13. Silber, R. H., and Porter, C. C. Nitrogen balance, liver protein repletion and body composition of cortisone treated rats. Endocrinology 1953, 52, 518.

14. Sprague, R. G., Power, M. H., Mason, H. L., Albert, A., Mathieson, D. R., Hench, P. S., Kendall, E. C., Slocumb, C. H., and Polley, H. F. Observations on the physiologic effects of cortisone and ACTH in man. Arch. intern. Med. 1950, 85, 199.

15. Kochakian, C. D., and Robertson, E. Corticoids and body and organ weights, nitrogen balance, and enzymes. J. biol. Chem. 1951, 190, 481.

16. Roberts, E., Ronzoni, E., and Frankel, S. Influence of ACTH on urinary secretion of amino acids. Cancer Res. 1951, 11, 275.

17. Clark, I. The effect of cortisone upon protein synthesis. J. biol. Chem. 1953, 200, 69.

18. White, A., and Dougherty, T. F. Role of the adrenal cortex and the thyroid in the mobilization of nitrogen from the tissues in fasting. Endocrinology 1947, 41, 230.

19. Baker, B. L., Ingle, D. J., Li, C. H., and Evans, H. M. Growth inhibition in the skin induced by parenteral administration of adrenocorticotropin. Anat. Rec. 1948, 102, 313.
20. Baker, B. L., and Ingle, D. J. Growth inhibition in bone and bone marrow following treatment with adrenocorticotropin (ACTH). Endocrinology 1948, 43, 422.

21. Becks, H., Simpson, M. E., Li, C. H., and Evans, H. M. Effect of adrenocorticotropic hormone (ACTH) on osseous system in normal rats. Endocrinology 1944, 34, 305.

22. Plotz, C. M., Howes, E. L., Blunt, J. W., Meyer, K., and Ragan, C. Action of cortisone on mesenchymal tissues. Arch. Derm. Syph. (Berl.) 1950, 61, 919.

23. Evans, H. M., Simson, M. E., and $\mathrm{Li}, \mathrm{C}$. H. Inhibiting effect of adrenocorticotropic hormone on growth of male rats. Endocrinology 1943, 33, 237.

24. Grossman, J., Yalow, A. A., and Weston, R. E. Effects of corticotropin, hydrocortisone, and stress on albumin synthesis and catabolism in man (abstract). J. clin. Invest. 1957, 36, 896.

25. Blythe, W. B., Iber, F. L., Werner, I., Rubini, M. E., Frick, P. G., and Meroney, W. H. The effect of hydrocortisone on simultaneously determined albumin turnover and nitrogen balance (abstract). Clin. Res. Proc. 1957, 5, 190.

26. McFarlane, A. S. Labelling of plasma proteins with radioactive iodine. Biochem. J. 1956, 62, 135.

27. Cohen, S., Holloway, R. C., Matthews, C., and McFarlane, A. S. Distribution and elimination of ${ }^{121} \mathrm{I}$ - and ${ }^{14} \mathrm{C}$-labelled plasma proteins in the rabbit. Biochem. J. 1956, 62, 143.

\section{SPECIAL NOTICE TO SUBSCRIBERS}

Post Offices will no longer forward the Journal when you move.

Please notify The Journal of Clinical Investigation, Business

Office, 333 Cedar Street, New Haven 11, Conn., at once when you have a change of address, and do not omit the zone number if there is one. 